\title{
Treadmill exercise alleviates short-term memory impairments of pups born to old and obese mother rats
}

\author{
Young Jun Ko* \\ Major in Sport Service Practice, College of Welfare Convergence, Kangnam University, Yongin, Korea
}

Obesity causes atrophy of the brain, leading to deterioration in working memory, learning, and cognitive function. The status of short-term memory in rat pups born to older obese mother rats was verified, and the effect of treadmill exercise on short-term memory in rat pups was investigated. Step-down avoidance test for short-term memory, terminal deoxynucleotidyl transferase-mediated dUTP nick end labeling (TUNEL) staining for apoptosis, and immunohistochemistry for Ki67 for new cell generation were done. The old female rats were fed with normal diet ( $5 \%$ of fat), and the old and obese female rats were fed with high-fat diet (60\% of fat) for up to 50 weeks in age (for 44 weeks in experimental period). The newborn rats were divided into four groups ac-

\section{INTRODUCTION}

Obesity causes atrophy of the brain, leading to deterioration in working memory, learning, and cognitive function. It is known that a high-fat diet reduces the flexibility of synapses in the cerebral cortex, thereby reducing brain function, including the permeability and function of the blood-brain barrier (Arnold et al., 2014).

The hippocampus, which is part of the brain's limbic system, incorporates many types of memory, especially short-term memory. The hippocampus generates new neurons, which are responsible for the formation and integration of hippocampal-dependent memories (Snyder et al., 2005). The step-down avoidance test was developed to detect short-term memory (Ji et al., 2020). Shortterm memory is a capacity that keeps a small amount of information in mind but does not manipulate it while it is active for a short period of time and is readily available.

Apoptosis plays an important role in normal development and cording to the conditions of the mother rats as follows: the rat pups group born to old rats, the rat pups group born to old rats with exercise, the rat pups group born to old and obese rats, the rat pups group born to old and obese rats with exercise. Maternal exercise improved shortterm memory, decreased TUNEL-positive cell number, and increased Ki67-positive cell number of the pups born to old and obese rats. Maternal exercise has been found to contribute to eliminating the health risks of fetuses born to old obese mothers.

Keywords: Older obese mother rats, Pups, Treadmill exercise, Shortterm memory, Apoptosis, New cell generation tissue homeostasis, which is a form of cell death that eliminates dying cells. However, inappropriate or excessive cell death is closely related to a number of diseases (Lee et al., 2003). Terminal deoxynucleotidyl transferase-mediated dUTP nick end labeling (TUNEL) is a technique that detects DNA fragmentation by labeling 3'-hydroxyl termini in double-strand DNA breaks generating during apoptosis (Gorczyca et al., 1993). TUNEL staining is used to detect DNA fragmentation, which is characteristics of apoptosis. Social isolation in old rats increased TUNEL-positive cell number, indicating that social isolation promoted apoptosis (Park et al., 2020b).

The Ki67 protein is present during all active stages of the cell cycle, such as G1, S, G2, and mitosis, but not in resting cells (G0). The Ki67 protein is markedly increased through the $\mathrm{S}$ phase of the cell cycle (Darzynkiewicz et al., 2015). The Ki67 protein is a marker for cellular proliferation (Scholzen and Gerdes, 2000) and Ki67 protein can be used for target protein of immunohistochemistry (Lee et al., 2016). The Ki67 antigen can only be detected
${ }^{\star}$ Corresponding author: Young Jun Ko (D https://orcid.org/0000-0001-5469-7235 Major in Sport Service Practice, College of Welfare Convergence, Kangnam University, 40 Gangnam-ro, Giheung-gu, Yongin 16979, Korea Email: ko0524@naver.com

Received: April 16, 2021 / Accepted: May 19, 2021
This is an Open Access article distributed under the terms of the Creative Commons Attribution Non-Commercial License (https://creativecommons.org/licenses/by-nc/4.0/) which permits unrestricted non-commercial use, distribution, and reproduction in any medium, provided the original work is properly cited. 
within the cell nucleus during interphase, whereas in mitosis, most proteins are rearranged to the chromosomal surface (Cuylen et al., 2016).

In this experiment, the status of short-term memory in rat pups born to older obese mother rats was verified, and the effect of treadmill exercise on short-term memory in rat pups was investigated. Step-down avoidance test for short-term memory, TUNEL staining for apoptosis, and immunohistochemistry for $\mathrm{Ki} 67$ for new cell generation were done.

\section{MATERIALS AND METHODS}

\section{Animals and classification}

This experiment was deliberated by the Animal Care and Use Committee (approval number: 20-135). Sixteen female rats of the 6-week-old Sprague-Dawley family were enrolled. The old female rats were fed with normal diet ( $5 \%$ of fat), and the old and obese female rats were fed with high-fat diet (60\% of fat) for up to 50 weeks in age (for 44 weeks in experimental period). For mating, at 46 weeks in age, Sprague-Dawley male rats (15 weeks old) were reared in the same cage for 7 days at the ratio of one female and two males. Female rats were divided into two groups: one group is old rats and the other group is old and obese rats $(n=8)$. Treadmill exercise was performed for a total of 23 weeks, including 20 weeks before induction of pregnancy and 3 weeks of pregnancy. Exercise intensity was performed for $20 \mathrm{~min}$ per day at a speed of $5 \mathrm{~m} / \mathrm{min}$. The newborn rats were divided into four groups according to the conditions of the mother rats as follows $(n=10)$ : the rat pups group born to old rats, the rat pups group born to old rats with exercise, the rat pups group born to old and obese rats, the rat pups group born to old and obese rats with exercise.

\section{Step-down avoidance test}

The step-down avoidance test was used to measure short-term memory as explained below (Park et al., 2020a). The rat pups were subjected to a step-down avoidance test after the final treadmill running. The rat pups were sited in a $60 \times 45 \times 25-\mathrm{cm}$ acrylic box with a $7 \times 25-\mathrm{cm}$ platform at the bottom of the box. After placing the rat pup on the platform, the time (latency) until it descended on the floor was measured. When the rat pup came down, a current of $0.5 \mathrm{~mA}$ was applied to the sole of the foot for $2 \mathrm{sec}$. Four hours after training, the latency of each rat was measured. The latency of $300 \mathrm{sec}$ or more was calculated as $300 \mathrm{sec}$.

\section{TUNEL staining}

TUNEL staining by a Cell Death Detection Kit (Roche, Mannheim, Germany) was used as explained below (Park et al., 2020b). The sections were treated with $100 \mathrm{mg} / \mathrm{mL}$ proteinase $\mathrm{K}$ and TUNEL reaction mixture, and counterstained with Nissl. Air-dry the slides overnight at room temperature and cover slips were used for mounting.

\section{Ki67 immunohistochemistry}

Immunohistochemistry for Ki67 was used as explained below (Lee et al., 2016). The sections were treated with mouse anticaspase-3 antibody (1:500; Santa Cruz Biotechnology, Dallas, TX, USA) overnight and mouse anti-Ki67 antibody (1:500; Novocastra Laboratories, Newcastle, UK). The sections were treated with the biotinylated mouse secondary antibody for another $1 \mathrm{hr}$. The Vector Elite ABC kit (1:200; Vector Laboratories) was used to amplify the secondary antibody. Air-dry the slides overnight at room temperature and cover slips were used for mounting.

\section{RESULTS}

\section{Short-term memory}

In the rat pups born to old and obese rats, the latency was suppressed compared to the rat pups group born to old rats. However, rat pups born to old and obese rats with exercise showed in-

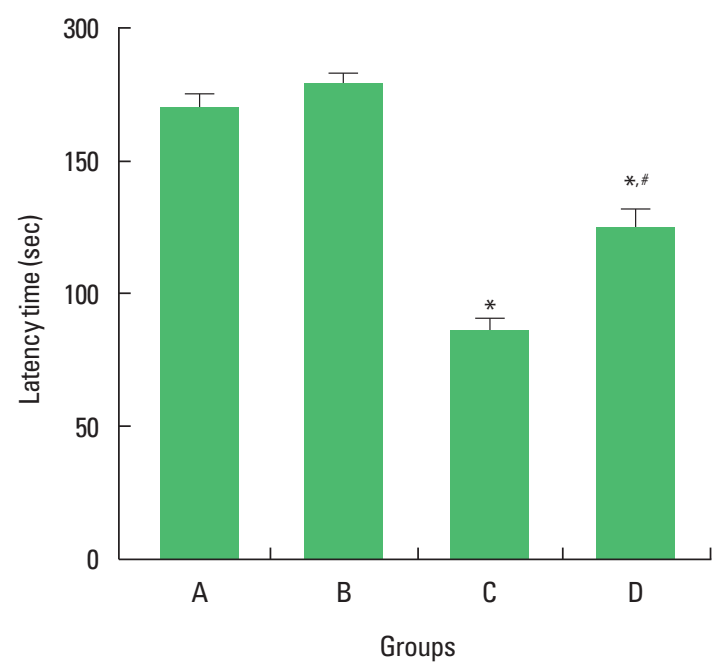

Fig. 1. Latency of step-down avoidance test. A, rat pups group born to old rats; $B$, rat pups group born to old rats with exercise; $C$, rat pups group born to old and obese rats; $D$, rat pups group born to old and obese rats with exercise. ${ }^{*} P<0.05$ compared with rat pups group born to old rats. ${ }^{\#} P<0.05$ compared with rat pups group born to old and obese rats. 
creased latency. These results mean that short-term memory was impaired in the rat pups born to old and obese rats, but maternal exercise improved short-term memory of the rat pups born to old and obese rats (Fig. 1).

\section{Apoptosis}

In the rat pups born to old and obese rats, the number of TUNEL-positive cells in the hippocampal dentate gyrus was enhanced compared to the rat pups born to old rats. However, rat pups born to old and obese rats with exercise showed decreased number of TUNEL-positive cells. These results mean that apoptosis was increased in the rat pups born to old and obese rats, but maternal exercise inhibited apoptosis of the rat pups born to old and obese rats (Fig. 2).
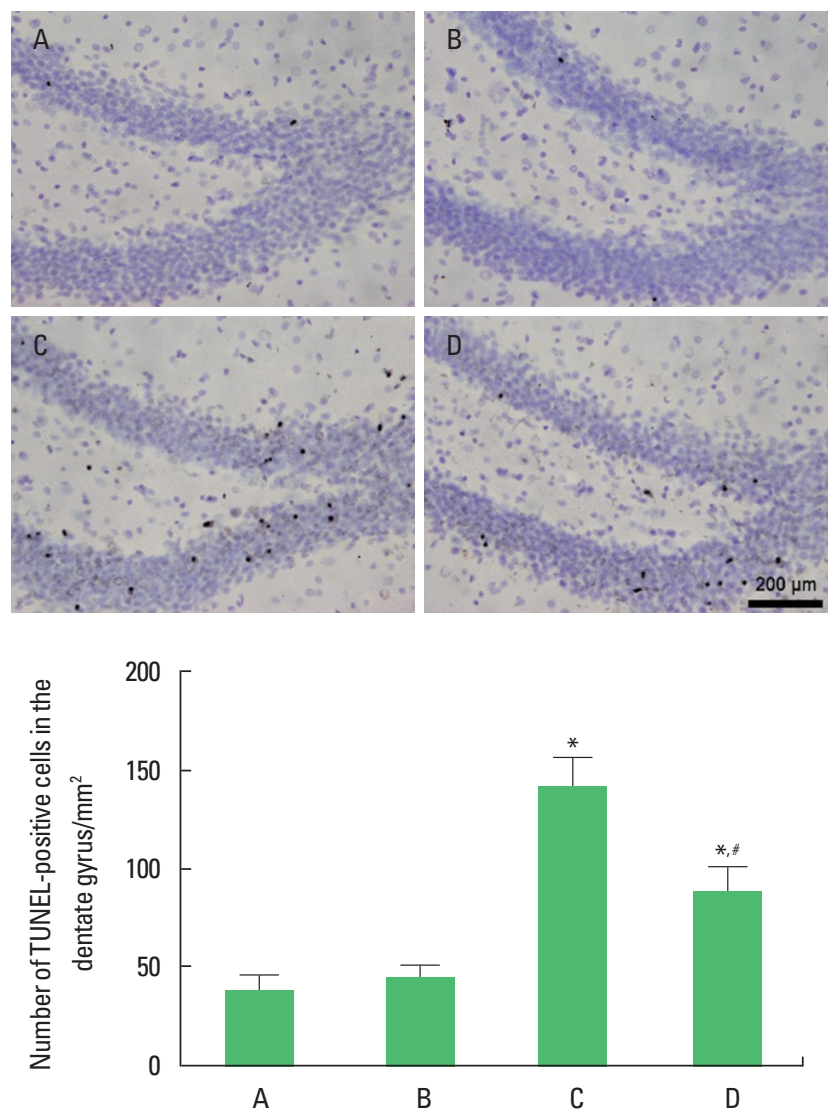

Fig. 2. Terminal deoxynucleotidyl transferase-mediated dUTP nick end labeling (TUNEL) staining in the hippocampal dentate gyrus. Upper panel: photomicrographs of TUNEL-positive cells. Lower panel: number of TUNEL-positive cells. $A$, rat pups group born to old rats; $B$, rat pups group born to old rats with exercise; $C$, rat pups group born to old and obese rats; $D$, rat pups group born to old and obese rats with exercise. ${ }^{*} P<0.05$ compared with rat pups group born to old rats. ${ }^{\#} P<0.05$ compared with rat pups group born to old and obese rats.

\section{New cell generation}

In the rat pups born to old and obese rats, the number of $\mathrm{Ki} 67$ in the hippocampal dentate gyrus was suppressed compared to the rat pups born to old rats. However, rat pups born to old and obese rats with exercise showed increase the number of Ki67. These results mean that new cell generation was decreased in the rat pups born to old and obese rats, however maternal exercise enhanced new cell generation of the rat pups born to old and obese rats (Fig. 3).

\section{DSCUSSION}

Obesity in pregnant mothers affects not only the weight at birth of the fetus, but also weight until the age of 4-7, which can
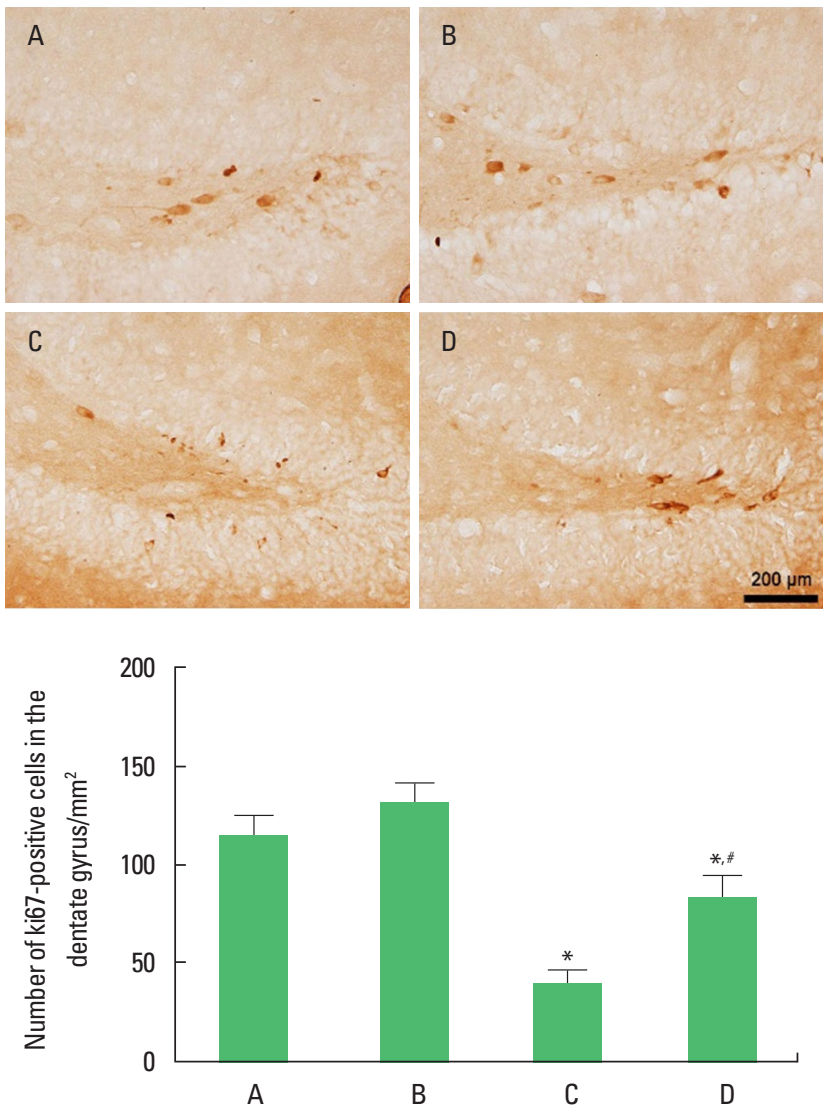

Fig. 3. Ki67 immunohistochemistry in the hippocampal dentate gyrus. Upper panel: photomicrographs of Ki67. Lower panel: number of Ki67 in the hippocampal dentate gyrus. A, rat pups group born to old rats; $B$, rat pups group born to old rats with exercise; $C$, rat pups group born to old and obese rats; $D$, rat pups group born to old and obese rats with exercise. ${ }^{*} P<0.05$ compared with rat pups group born to old rats. ${ }^{\# P}<0.05$ compared with rat pups group born to old and obese rats. 
be explained because it depends on the supply of nutrition through the fetus or breast milk during the early stages of birth. One study looked at whether older adults had short-term memory deficits. They found that participants aged 55 to 85 had a disability (Fournet et al., 2012).

Performing swimming of maternal rats during pregnancy improved short-term memory by increasing the production of nerve cells in offspring (Lee et al., 2006). Treadmill running during pregnancy improved brain function in offspring (Kim et al., 2007). Short-term memory in pups born to obese rats was impaired, but treadmill exercise during pregnancy improved shortterm memory due to increasing neurogenesis in pups born to obese rats (Ji et al., 2020). In the current study, short-term memory was deteriorated in the pups born to old and obese rats, however, maternal exercise improved short-term memory of the pups born to old and obese rats.

In social isolation rats, TUNEL-positive cell number was increased (Park et al., 2020b). Swimming inhibited TUNEL-positive cell number, representing swimming exercise inhibited apoptosis in social isolation-induced apoptosis (Park et al., 2020b). In the current study, apoptosis in the hippocampal dentate gyrus was enhanced in the pups born to old and obese rats, however, maternal exercise suppressed apoptosis of the pups born to old and obese rats.

In autism-induced rat pups, Ki67-positive cell number in the hippocampal dentate gyrus was decreased and short-term memory was impaired (Lee et al., 2016). However, Ki67-positive cell number was enhanced and short-term memory impairment was alleviated in autism-induced rat pups exposed to music (Lee et al., 2016). In the current study, new cell generation in the hippocampal dentate gyrus was suppressed in the pups born to old and obese rats, however, maternal exercise enhanced new cell generation of the pups born to old and obese rats.

In this study, short-term memory was decreased, apoptosis was increased, and the number of new neurons was suppressed in rat pups born from old and obese mother rats. Maternal exercise has been found to contribute to eliminating the health risks of fetuses born to old obese mothers.

\section{CONFLICT OF INTEREST}

No potential conflict of interest relevant to this article was reported.

\section{ACKNOWLEDGMENTS}

The authors received no financial support for this article.

\section{REFERENCES}

Arnold SE, Lucki I, Brookshire BR, Carlson GC, Browne CA, Kazi H, Bang S, Choi BR, Chen Y, McMullen MF, Kim SF. High fat diet produces brain insulin resistance, synaptodendritic abnormalities and altered behavior in mice. Neurobiol Dis 2014;67:79-87.

Cuylen S, Blaukopf C, Politi AZ, Müller-Reichert T, Neumann B, Poser I, Ellenberg J, Hyman AA, Gerlich DW. Ki-67 acts as a biological surfactant to disperse mitotic chromosomes. Nature 2016;535:308-312.

Darzynkiewicz Z, Zhao H, Zhang S, Lee MY, Lee EY, Zhang Z. Initiation and termination of DNA replication during $S$ phase in relation to cyclins D1, E and A, p21WAF1, Cdt1 and the p12 subunit of DNA polymerase $\delta$ revealed in individual cells by cytometry. Oncotarget 2015;6:11735-11750.

Fournet N, Roulin JL, Vallet F, Beaudoin M, Agrigoroaei S, Paignon A, Dantzer C, Desrichard O. Evaluating short-term and working memory in order adults: French normative data. Aging Ment Health 2012; 16:922-930.

Gorczyca W, Traganos F, Jesionowska H, Darzynkiewicz Z. Presence of DNA strand breaks and increased sensitivity of DNA in situ to denaturation in abnormal human sperm cells. Analogy to apoptosis of somatic cells. Exp Cell Res 1993;207:202-205.

Ji ES, Kim YM, Ko YJ, Baek SS. Treadmill exercise in obese maternal rats during pregnancy improves short-term memory through neurogenesis in the hippocampus of rat pups. J Exerc Rehabil 2020;16:392-397.

Kim H, Lee SH, Kim SS, Yoo JH, Kim CJ. The influence of maternal treadmill running during pregnancy on short-term memory and hippocampal cell survival in rat pups. Int J Dev Neurosci 2007;25:243-249.

Lee HH, Kim H, Lee JW, Kim YS, Yang HY, Chang HK, Lee TH, Shin MC, Lee MH, Shin MS, Park S, Baek S, Kim CJ. Maternal swimming during pregnancy enhances short-term memory and neurogenesis in the hippocampus of rat pups. Brain Dev 2006;28:147-154.

Lee MH, Kim H, Kim SS, Lee TH, Lim BV, Chang HK, Jang MH, Shin MC, Shin MS, Kim CJ. Treadmill exercise suppresses ischemia-induced increment in apoptosis and cell proliferation in hippocampal dentate gyrus of gerbils. Life Sci 2003;73:2455-2465.

Lee SM, Kim BK, Kim TW, Ji ES, Choi HH. Music application alleviates short-term memory impairments through increasing cell proliferation in the hippocampus of valproic acid-induced autistic rat pups. J Exerc Rehabil 2016;12:148-155.

Park SS, Kim TW, Park HS, Seo TB, Kim YP. Effects of treadmill exercise 
on activity, short-term memory, vascular dysfunction in maternal separation rats. J Exerc Rehabil 2020a;16:118-123.

Park SS, Park HS, Kim TW, Lee SJ. Effects of swimming exercise on social isolation-induced memory impairment and apoptosis in old rats. J Exerc Rehabil 2020b;16:234-241.
Scholzen T, Gerdes J. The Ki-67 protein: from the known and the unknown. J Cell Physiol 2000;182:311-322.

Snyder JS, Hong NS, McDonald RJ, Wojtowicz JM. A role for adult neurogenesis in spatial long-term memory. Neuroscience 2005;130:843852. 